\title{
Benefit's Portfolio in a Company in Connection to the Generation of Managerial Applicants
}

\author{
Kateřina Jančíková ${ }^{1}$ and František Milichovský ${ }^{1, *}$ \\ ${ }^{1}$ Department of Economics, Faculty of Business and Management, Brno University of Technology, \\ Brno, Czech Republic
}

\begin{abstract}
The topic of remuneration of executive managers (included $\mathrm{CEO}$ ) is considered such a key factor of personal management (PM). The issue of remuneration of high-ranking managers is a key area of personnel management and corporate governance. This is still a much-discussed topic, which seeks to answer the most important question: How to set management rules in companies so that all stakeholders behave effectively? It is high-ranking managers who are a specific group in which the creation of a remuneration contract must ensure the optimal connection of their performance with measurable indicators of the company. The consequences of their decisions can be clear for up to several years, so setting optimal benchmarks is more than important. The main aim of the research paper was to find a dependence between the type of respondent generation and the sought-after benefits in the managerial position. The hypothesis was defined as follows: the type of respondent generation influences the choice of benefit. IBM SPSS Statistics 25 was used to process and evaluate the data obtained from the structured questionnaire survey. The mathematical-statistical methods used to verify the dependence between selected variables were used the Chi-square test of independence of two variables.
\end{abstract}

Keywords: benefits and remuneration; motivation; corporate identity; human resource management

\section{Introduction}

Today, the company's reputation and reputation is not only related to its business practices and is not only influenced by customer satisfaction. Nowadays, great emphasis is placed on employees and their satisfaction, as employees are bearers of the brand. Each employee is unique, has specific characteristics, skills, and abilities that influence his / her behavior, values, and attitudes. These can be a source of high performance for the organization. Therefore, to maximize employee performance and ensure that it proudly presents the brand of the organization, it is necessary to motivate the employee correctly. The structure of workers has also changed considerably recently and the labor market is dominated by $\mathrm{Y}$ and $\mathrm{Z}$ generation. They are young people whose perception of work performance, motivation, and benefits differ significantly from the traditional conception

*Corresponding author: milichovsky@fbm.vutbr.cz 
recognized by Generation X. freedom, the possibility of self-realization and the benefits they demand are primarily non-monetary and intangible. The following chart shows the change in the population structure in the Czech Republic over the next decade. More and more Z-workers will accumulate in the labor market, and it is now necessary to change the minds of company representatives and move from traditional forms of motivation and remuneration to new ways. According to Forbes (2019), generation X includes people born 1968-1982, generation Y includes people born 1983-1997, and generation Z includes people born after 1998 .

The purpose of this article is to create a conceptual framework that will help HR managers and business owners to positively influence corporate identity through employee motivation and benefits provided. The article first defines the corporate reputation, then motivation and last but not least defines the specific characteristics of the $\mathrm{Z}$ generation, which is becoming new blood for the labor market. The article will present data and results of the research conducted in the Czech work environment. The second part of the paper describes the methodology and employed methods. The third part presents gained results with relevant discussion and finally, there is a conclusion of the paper.

\section{Theoretical background}

Every organization, regardless of size, has its own corporate identity (Balmer, Gray, 2003; Olins, 1989) and we understand an organization as any form of the profit-making institution (Boulton, Allen, Bowman, 2015). As a result, the concept of corporate identity can be applied very widely. The notion of corporate identity is not precisely defined (Kitchen et al., 2013; Leitch, Motion, 1999; Melewar, 2003). In general, corporate identity can be seen as the "essence of society" (Olins, 1978). The core values of the company are a central aspect of the corporate identity and initially come from the founders (Urde, 2003). Over time, however, corporate identity and company values change under the influence of several stakeholders, including employees (Iglesias et al., 2013). Human resources are becoming increasingly important for the impact of the social reputation of the organization. World studies show the impact of the ability to recruit talented employees on improving the company's reputation (Clardy, 2005; Turban, Cable, 2003), further improved corporate reputation through fair treatment (Koys, 1997; Shaughnessy, 2005). A conceptual framework that combines the role of HR and the company's reputation appears in its culture. The human resources function plays an important role in organizations where intellectual capital represents a competitive advantage for the company. Examples of such companies are Google or Intel, where great emphasis is placed on employee motivation and satisfaction (Friedman, 2009).

The role of employee champion maximizes employee benefit by responding to workers' concerns and allowing them to increase competencies in line with the organization's goals (Ulrich, 1997). Employee champion addresses a wide range of working conditions that increase employee loyalty, such as pay, pay, safety and job satisfaction, effective training, career planning and mentoring, etc. Employee champions at Wegmans (a private food chain based in New York) indirectly improved the company's reputation and financial performance. Wegmans ranked in the 1st position in the Fortune Magazine's 100 Best Companies in 2005, ranked 2nd in 2006 and 3rd in 2007. This company provides generous employee benefits, including a scholarship program for universities. This assistance is provided to more than 19,000 employees in a lot of $\$ 59$ million. The program encourages all employees to pursue their educational goals, promote upward career mobility, a good community, and improve Wegmans' reputation as the number one employer for all people (Wegmans, 2007; Cesari, Gonenc, Ozkan, 2016). For this company, employees come first, and customers come second. Another company that takes great care of its employees is 
Google. It is regularly ranked worldwide among the best employer rankings. In this company, they are committed to a work environment that is designed to maximize employee productivity, loyalty, and creativity. Google is characterized by low employee turnover because work and the environment are appealing to employees and want to stay in the company (Friedman, 2009). This company is also an attractive employer for the youngest generation of $Z$.

So far, Generation $Z$ has been viewed "only" as young customers. Now all of this generation is entering the labor market, raising awareness of this generation as colleagues and employees. Each generation is specific and has its basic characteristics. Generation $\mathrm{Z}$ members demand respect and want to be treated as partners, not as traditional employees. A typical characteristic is the requirement of freedom to perform their work, which has so far usually been reserved for senior positions. They also have a choice of working time and contact with people outside their work. If the employer grants them such working conditions, then these workers will be rewarded with a great work commitment, unexpected independence, and purposefulness (Volek, 2018).

According to the latest surveys, up to 9 out of 10 employees occasionally monitor job offers, which means that if an employer wants to retain their employees, they must do their utmost to understand their values, needs, and remuneration, as well as the incentive to adapt (Clifford, 2014). Money is important to the new generation Z, but that's not all. Therefore, working conditions, good relationships with colleagues, praise or appreciation, teamwork, or meaningfulness of work also play an important role in the decision-making process.

Both $\mathrm{Y}$ and $\mathrm{Z}$ are aware of the challenges they face. They assume that it will not be easy to find employment at the time of emerging Industry 4.0, but they believe they will be better off than their parents. Thus, $\mathrm{Z}$ can be even more optimistic than the $\mathrm{Y}$ generation (Deloitte, 2018). According to a survey by Ozkan and Solmaz (2015), the social environment is very important for the $\mathrm{Z}$ generation. This is also an important factor in building a corporate culture. The survey also showed that this generation is very confident and understands work as a means to achieve their dreams. If they are not satisfied at work, they can easily leave the job. They are not afraid of uncertainty about losing their job.

The purposefulness of the $Z$ generation directs these workers to high positions in companies that can reach them very quickly. The negative of this generation is lower loyalty to their employers and more frequent change of employer. All the more this fact will manifest itself when the company motivation program is not aligned with the priorities of these employees. For example, if a company is only fixed to generate its profits, then it loses loyalty to its employees (Deloitte, 2018). Figure 1 shows the factors for which the respondents of the performed research should sort the individual aspects according to their importance when considering work in the selected company. The survey was attended by 10,455 millenniums and 1,844 workers from the $\mathrm{Z}$ generation. However, this is in line with the idea that business owners should share their wealth with their employees. It also reflects the fact that the $\mathrm{Y}$ and $\mathrm{Z}$ generation must think more about their future and the security of their future family (Deloitte, 2018). 


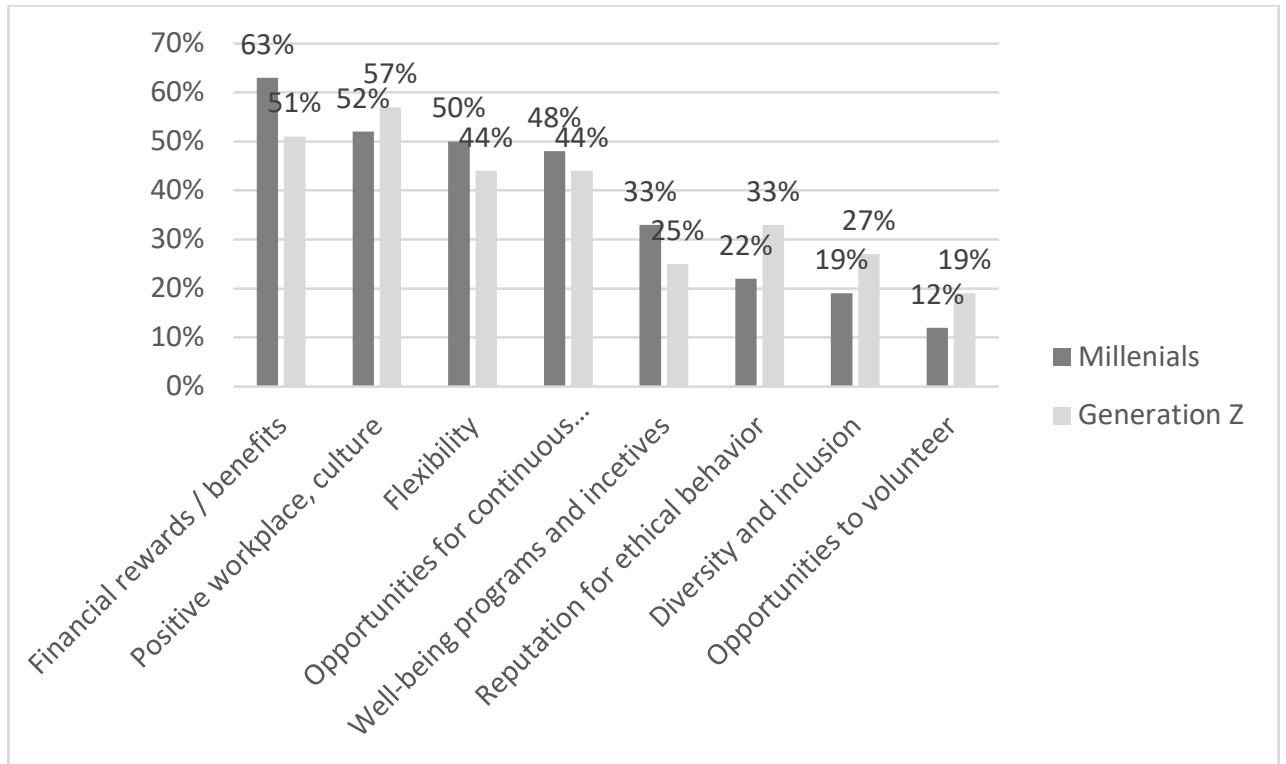

Fig. 1. Important aspects of work for the $\mathrm{Y}$ and $\mathrm{Z}$ generations Source: Own processing.

According to a PWC survey (2019b), CEOs are very aware that there is a shortage of skilled workers in the labor market, so they need to be interested in something. However, each employee has his / her specific needs and offering each employee a special incentive program is not very realistic in the business environment. Therefore it is necessary to focus on groups of employees, e.g. according to generational classification, as described above in the article. To retain employees, managers and CEOs will have to take on non-traditional forms of work. These will not only reflect flexible cooperation models but will also reflect the new population structure.

The new forms of benefits currently appearing in the labor market, as well as wage increases, reflect the growth of the economy and CEO's expectations. According to a PWX survey (2019a), more than 50\% of CEOs expect the economy to grow in the coming period. When comparing Czech CEOs and world CEOs, the Czechs are more optimistic about the future outlook for the world economy (PWC, 2019c), 70\% of CEOs believe globally in the growing economic development, while $85 \%$ of CEOs believe in the Czech environment.

The attractiveness of the company in the labor market is also ensured by the efforts of employers to respect the needs of their employees. These needs (priorities) change over time and their hierarchy also changes. The general breakdown includes monetary (material) and value (non-material). Employee satisfaction consists of 3 components and the wage addresses only the basic needs of the employee. The second part of the satisfaction is the feeling of belonging, which is very closely connected with the corporate culture. The last part is the work itself (Chrenko, 2019). If all 3 components are set correctly, then employee satisfaction is greatly increased. According to a survey conducted by the Gallup Institute in 2017 on employee satisfaction, the 2 nd and 3rd components have an impact of up to $87 \%$ on employee engagement and business productivity growth of up to $30 \%$ (Chrenko, 2019).

It can be expected that specific characteristics of a business, such as size or level of risk, will strongly affect performance compensation. Many authors have already empirically demonstrated the relationship between the size of a business and the level of management's remuneration and CEOs (Rosen, 1992; Murphy, 1985; Zhou, 2000; Ryan, Wiggins, 2001). According to Murphy (1999) and Song and Wan (2017), it is possible to read that the 
sensitivity between performance and manager's salary is weaker among larger American companies.

\section{Methodology}

The main aim of the research paper was to find a dependence between the type of respondent generation and the sought-after benefits in the managerial position and CEO. The chosen benefits are in Table 1.

Table 1. The dividing of chosen benefits as individual variables

\begin{tabular}{|c|c|c|c|}
\hline \multirow{2}{*}{ Tangible benefits } & company car & company laptop & \\
\cline { 2 - 4 } & $\begin{array}{c}\text { financial } \\
\text { contribution }\end{array}$ & $\begin{array}{c}\text { company mobile } \\
\text { phone }\end{array}$ & \\
\hline \multirow{2}{*}{$\begin{array}{c}\text { Non-tangible } \\
\text { benefits }\end{array}$} & $\begin{array}{c}\text { proportionate } \\
\text { ownership }\end{array}$ & home office & sick days \\
\cline { 2 - 4 } & extra holidays & employer brand & \\
\hline
\end{tabular}

Source: Own processing.

The hypothesis was defined as follows:

- $\mathrm{H}_{0}$ : the type of respondent generation does not affect the choice of benefit;

- $\mathrm{H}_{1}$ : the type of respondent generation influences the choice of benefit.

IBM SPSS Statistics 25 was used to process and evaluate the data obtained from the structured questionnaire survey. The statistical methods were used to verify the dependence between selected variables by Pearson Chi-square test of independence. This test is used to monitor the relationship between selected variables. To confirm the alternative hypothesis (that is, there is a relationship between defined variables) we have chosen a significance level of $95 \%$.

Data for this research were obtained through a structured questionnaire survey, which included both open and closed questions. The questionnaire survey was realized in January 2020. The basic population included 925 students of the Brno University of Technology, who have the potential to become senior managers in companies. Number of all students, which are divided into individual study level refer to individual generation. Master students could be included to generation $\mathrm{Y}$ and master students are consist in generation $\mathrm{Z}$. Individual generations have different abilities, which are required at managerial positions. The difference between both groups are based on study programs, because bachelors' programs are made as professional programs and graduates are prepared for managerial work in various areas (e.g. accounting and taxes, production, ITC area, medium managerial positions in companies). The master programs includes parts, connected to managerial work and also prepare graduates for scientific work. In the long-term, both groups of bachelor and master students are almost similar. 522 respondents were randomly selected from the sample, with $50 \%$ of the respondents being Y population and $50 \%$ were respondents from the $\mathrm{Z}$ population. The reason for this dividing is that both generations are equal as the workforce with relevant offer to employer. Generation Y provides experiences is the most important thing, generation $\mathrm{Z}$ gives IT knowledge as its nature.

The return rate of the questionnaire survey was $34.48 \%$, i.e. 184 fully completed questionnaires. Due to missing data, 5 questionnaires were excluded from the evaluation. Respondents of population Y represented 41\% (73 respondents) and respondents of population $\mathrm{Z}$ represented 59\% (112 respondents). The study among graduates of Brno University of Technology, which declares that within two years after graduation, will reach 3 out of 10 graduates in managerial positions (Brno University of Technology, 2018), proves that this is a correctly selected group of respondents. 


\section{Results}

The relevance of benefits as part of the remuneration is based on several studies such as Castilla (2011), Dobbin et al. (2011), or Tomaskovic-Devey (2014). Test for independence (Pearson's chi-square) was employed to examine the stated hypothesis. The main base for verification is created a pivot table, showing frequencies of answers from individuals in connection to their generation. In the labor market, there are two main generations, which are prepared to become CEO soon. It is obvious from table 1, that tangible benefits are more preferred by both generations of workers in comparison to intangible benefits. All tangible benefits are acceptable by more than three-quarters of respondents in both generations. The main reason could be to "touch" the benefit. For intangible benefits, it is possible to corroborate the relevance of extra holiday and sick-days such an important part of the reward in an organization. According to the values in table 2, it is interesting, that both generations require the correct brand of their company.

Table 2. Pivot table of chosen benefits and individual generations

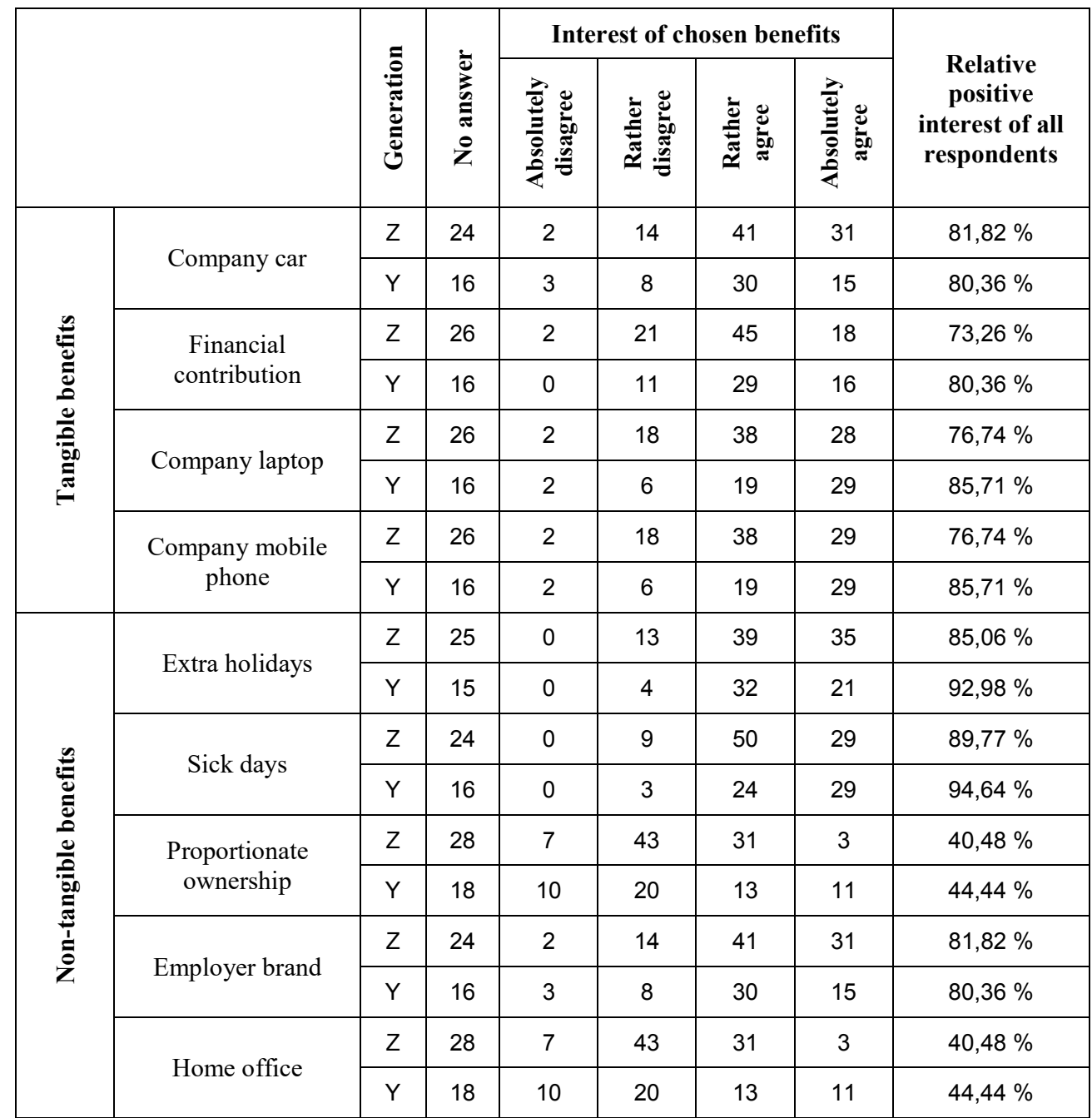

Source: Own processing. 
According to respondents' answers (see Table 2), it is obvious, that millennials prefer such benefits, which can support their families and provide them more time to be with family (mainly financial contribution, extra holidays, and sick-days). Generation $\mathrm{Z}$ prefers these benefits, which offer the kind of freedom for company financial sources (company car, extra holidays, sick days). On the contrary, for proportionate ownership and home office usually, both generations do not look for. Possibility of a home office is more preferred by employers in a stressful era such is during the COVID-19 situation, where a lot of companies used home-office instead of reducing staff (Papagiannidis, Marikyan, 2020; Zhang et al., 2020).

In the results of Pearson's chi-square test of independence, there are proved nine benefits in connection to the generation of applicants. From these nine connections, there are found only three relations, which could be considered as statistical dependencies reach a significant $\mathrm{p}$-value under 0,05 . In the results of the Pearson's chi-square test of independence (see Table 3), there are found out dependencies between (these results match the required level of significance of potential error under $5 \%$ ):

- $\quad$ generation and proportionate ownership ( $\mathrm{p}$-value $=0,005)$;

- $\quad$ generation and employer brand ( $\mathrm{p}$-value $=0,001)$;

- $\quad$ generation and home office ( $p$-value $=0,033)$.

The p-value, which expresses the probability of validity of the null hypothesis. The lower the p-value, the lower the probability of a null hypothesis. It can, therefore, be concluded from the above data that we can only accept alternative hypotheses about the validity of the relationship between gender and selected sources of job offers only for job servers and social networks. Furthermore, we should consider the level of significance chosen. We are working with a 5\% significance level in the paper, so the p-value should be lower than this significance level. Only for social networks the p-value $<\alpha=0.05$, therefore we reject the null hypothesis and accept the alternative hypothesis about the dependence of selected elements.

Other benefits, which were verified for dependence with the generation, did not meet dependence with defined generations of applicants. Their $\mathrm{p}$-values were over the required $5 \%$ error. There are two benefits, which significances are close to the relevant value (in comparison to others); company laptop has $\mathrm{p}$-value 0,175 and sick days reach $\mathrm{p}$-value for 0,152 . Both values are high, but they could be put under the monitoring process and revised. From others point of the view, did not prove relevant $\mathrm{p}$-values, which are accepted on the level of confidence $95 \%$ because they are higher than 0,4 .

The intensity of gained dependencies is defined by the contingency coefficient, which can be in interval $<0 ; 1>$. Gained coefficients for observed dependencies are as follow (all values are shown in Table 3 ):

- generation and proportionate ownership has intensity 0,275 , which is described as rather low value;

- generation and employer brand reaches intensity 0,310 , which is described as low value;

- generation and home office have intensity 0,232 , which is described as a rather low value.

These three relationships could steady the planning of human resources, benefit offering, and hire relevant applicants, the fittest for a job position. 
Table 3. Pearson's test of the relationship between chosen benefits and generations ( $\mathrm{Y}$ and $\mathrm{Z}$ )

\begin{tabular}{|c|c|c|c|c|}
\hline & & & value & p-value \\
\hline \multirow{8}{*}{ 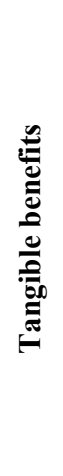 } & \multirow{2}{*}{ Company car } & Pearson Chi-Square & 2,110 & 0,716 \\
\hline & & Contingency Coefficient & 0,106 & \\
\hline & \multirow{2}{*}{$\begin{array}{l}\text { Financial } \\
\text { contribution }\end{array}$} & Pearson Chi-Square & 2,506 & 0,644 \\
\hline & & Contingency Coefficient & 0,116 & \\
\hline & \multirow{2}{*}{ Company laptop } & Pearson Chi-Square & 6,336 & 0,175 \\
\hline & & Contingency Coefficient & 0,182 & \\
\hline & \multirow{2}{*}{$\begin{array}{l}\text { Company mobile } \\
\text { phone }\end{array}$} & Pearson Chi-Square & 1,888 & 0,756 \\
\hline & & Contingency Coefficient & 0,101 & \\
\hline \multirow{10}{*}{ 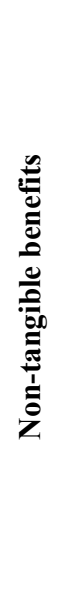 } & \multirow{2}{*}{ Extra holidays } & Pearson Chi-Square & 2,896 & 0,408 \\
\hline & & Contingency Coefficient & 0,124 & \\
\hline & \multirow{2}{*}{ Sick days } & Pearson Chi-Square & 5,289 & 0,152 \\
\hline & & Contingency Coefficient & 0,167 & \\
\hline & \multirow{2}{*}{$\begin{array}{l}\text { Proportionate } \\
\text { ownership }\end{array}$} & Pearson Chi-Square & 15,051 & 0,005 \\
\hline & & Contingency Coefficient & 0,275 & \\
\hline & \multirow{2}{*}{ Employer brand } & Pearson Chi-Square & 19,322 & 0,001 \\
\hline & & Contingency Coefficient & 0,310 & \\
\hline & \multirow{2}{*}{ Home office } & Pearson Chi-Square & 10,459 & 0,033 \\
\hline & & Contingency Coefficient & 0,232 & \\
\hline
\end{tabular}

Source: Own processing.

\section{Conclusions}

Benefit offer helps companies to care about current staff and due to its portfolio could catch relevant applicants from various generation type (Bolton et al., 2013). In general, both generations $\mathrm{Y}$ and $\mathrm{Z}$ look mainly for tangible benefits to reach certitude. From non-tangible benefits become more important company brand in connection to internal corporate culture and work environment, and to help create corporate identity supporting the brand. In the case of a high-quality company brand, employees change their mindset and their loyalty to the company have become much stronger and higher (Benraïss-Noailles, Viot).

The main aim of the research paper was to find a dependence between the type of respondent generation and the sought-after benefits in the managerial position and CEO. According to our results, we found out that there are three dependencies between analyzed generations Y and Z, and (1) proportionate ownership, (2) employer brand, and (3) home office. Their intensities are at low levels. Due correct setup of benefits portfolio it is possible to create relevant competitive advantage because the importance of human capital corroborates corporate strategies on the way of making good internal culture with linking to benefits' portfolio, corporate values, and strategic vision, and mission (Schnidman, Hester, 
Plunkte, 2017). A similar situation confirms the work of Gašková (2020) under the condition of a Czech university alumni condition.

The main limitation of the study is focused on the Czech environment, where we chose university students and graduates as potential applicants of managerial jobs. Our results could be adequate for alike countries as Slovakia, Poland, Hungary or Ukraine are.

\section{References}

1. J. M. T. Balmer, S. Greyser, Revealing the Corporation: Perspectives on Identity, Image, Reputation, Corporate Branding, and Corporate-level Marketing: An anthology. London: Routledge (2003)

2. L. Benraïss-Noailles, C. Viot, Employer brand equity effects on employees well-being and loyalty. Journal of Business Research, (2020) 10.1016/j.jbusres.2020.02.002 (IN PRESS)

3. R. N. Bolton, A. Parasuraman, A. Hoefnagels, N. Migchels, S. Kabadayi, T. Gruber, Y. Komarova Loureiro, D. Solnet, Understanding Generation Y and their use of social media: a review and research agenda. Journal of Service Management, 24(3), 245-267. (2013) 10.1108/09564231311326987

4. J. G. Boulton, P. M. Allen, C. Bowman, Embracing Complexity: Strategic Perspectives for an Age of Turbulence. Oxford: Oxford University Press. (2015)

5. A. Clardy, Reputation, goodwill and loss: Entering the employee training audit equation. Human Resource Development Review, 4(3), 279-304. (2005) $10.1177 / 1534484305278243$

6. C. Clifford, What Young People Want From Work. [online] Available at: https://www.entrepreneur.com/article/234934 (2014)

7. A. De Cesari, H. Gonenc, N. Ozkan, The effects of corporate acquisitions on CEO compensation and CEO turnover of family firms. Journal of Corporate Finance, 38, 294-317. (2016) 10.1016/j.jcorpfin.2016.01.017.

8. Deloitte. Deloitte Millennial Survey: Millennials disappointed in business, unprepared for Industry 4.0. [online] Available at: https://www2 .deloitte.com/content/dam/Deloitte/global/Documents/About-Deloitte/gx2018-millennial-survey-report.pdf (2018)

9. D. J. Flanagan, K. C. O'Shaughnessy, The effect of layoffs on firm reputation. Journal of Management, 31(3), 445-463. (2005) 10.1177/0149206304272186.

10. B. Friedman, Human resource management role implications for corporate reputation. Corporate Reputation Review, 12, 229-244. (2009) 10.1057/crr.2009.17.

11. J. Gašková, Servant leadership and its relation to work performance. Central European Business Review, 9(3), 24-37. (2020) 10.18267/j.cebr.236

12. O. Iglesias, N. Ind, M. Alfaro, The organic view of the brand: A brand value cocreation model. Journal of Brand Management, 20(8), 670-688. (2013) 10.1057/bm.2013.8.

13. P. J. Kitchen, M. Tourky, D. Dean, A. S. Shalaan, Corporate identity antecedents and components: Toward a theoretical Framework. Corporate Reputation Review, 16(4), 263-284. (2013) 10.1057/crr.2013.18.

14. D. J. Koys, Human resourced management and fortune's corporate reputation survey. Employee Responsibilities and Rights Journal, 10(2), 93-101. (1997) 10.1023/A:1025632711742. 
15. S. Leitch, J. Motion, Multiplicity in corporate identity strategy. Corporate Communications: An International Journal, 4(4), 193-199. (1999) 10.1108/13563289910299319.

16. T. C. Melewar, Determinants of the corporate identity construct: A review of the literature. Journal of Marketing Communications, 9(4), 195-220. (2003) 10.1080/1352726032000119161.

17. K. J. Murphy, Corporate performance and managerial remuneration: an empirical analysis. Journal of Accounting and Economics, 7(1-3), 11-42. (1985) 10.1016/01654101(85)90026-6.

18. W. Olins, Corporate identity-making business strategy visible through design. London: Thames and Hudson. (1989)

19. W. Olins, Corporate personality: An inquiry into corporate identity. New York: Mayflower Books. (1978)

20. M. Özkan, B. Solmaz, The changing face of the employees- generation $z$ and their perception of work (A study applied to university students). Procedia Economics and Finance, 26, 476-483. (2015) 10.1016/S2212-5671(15)00876-X

21. S. Papagiannidis, D. Marikyan, Smart offices: A productivity and well-being perspective. International Journal of Information Management, 51, 1-11. (2020) 10.1016/j.jijinfomgt.2019.10.012

22. S. Rosen, Contracts and the market for executives in contract economics. Blackwell Publishers. (1992)

23. H. E. Ryan, R. A. Wiggins, The influence of firm and manager-specific characteristics on the structure of executive compensation. Journal of Corporate Finance, 7(2), 101123. (2001) 10.1016/S0929-1199(00)00021-3

24. A. Schnidman, L. Hester, P. Plunkte, (2017). Global recruiting trends 2017 - What you need to know about the state of talent acquisition. [online] Available at: https://hrs.wsu.edu/wp-content/uploads/2015/09/linkedin-global-recruiting-trendsreport.pdf (2017).

25. W.-L. Song, K.-M. Wan, Explicit employment contracts and CEO compensation. Journal of Corporate Finance, 44, 540-560. (2017) 10.1016/j.jcorpfin.2014.11.002

26. D. B: Turban, D. M. Cable, Firm reputation and applicant pool characteristics. Journal of Organizational Behavior, 24(6), 733-750. (2003) 10.1002/job.215

27. D. Ulrich, HR Champions. Boston, MA: Harvard Business Press. (1997)

28. M. Urde, Core value-based corporate brand building. European Journal of Marketing, 37(7/8), 1017-1040. (2003) 10.1108/03090560310477645

29. M. Volek, Mladi Češi jako zaměstnanci: Cílevědomější, než se zdají. [online] Available at: https://www.ipsos.com/cs-cz/mladi-cesi-jako-zamestnanci-cilevedomejsinez-se-zdaji (2018)

30. S. X. Zhang, Y. Wang, A. Rauch, F. Wei, Unprecedented disruption of lives and work: Health, distress and life satisfaction of working adults in China one month into the COVID-19 outbreak. Psychiatry research, 288, 1-6. (2020) 10.1016/j.psychres.2020.112958

31. X. Zhou, CEO pay, firm size, and corporate performance: evidence from Canada. Canadian Journal of Economics, 33(1), 213-251. (2000) 10.1111/0008-4085.00013 